\title{
Investigation of the Microstructures and Mechanical Properties of Thin 5083 Aluminum Alloy Plates Welded by Double Pulse Gmaw Method
}

\author{
Gökçe Mehmet Gençer ${ }^{1}$, Fatih Kahraman, 2, Coşkun Yolcu , Ayça D. \\ Kahraman $^{4}$ and Ali Demircioğlu \\ 1,2,3,5 Mechanical Engineering Department, Dokuz Eylül University, İzmir, Turkey \\ ${ }^{4}$ Mechanical Engineering Department, Manisa Celal Bayar University, Manisa, Turkey \\ *Corresponding author
}

\begin{abstract}
In order to be able to use energy more efficiently, weight reduction solutions in machines, especially used in transportation, are sought by researchers. Aluminum alloys that are one of the light engineering alloys are commonly used in aerospace, automotive and sheet metal industry where the welding of thin plates is very important. Aluminum and its alloys have low weldability due to some characteristic properties such as high thermal conductivity, high electrical conductivity and the insulating oxide layer that has very high melting temperature compared to aluminum. The weldability of thin aluminum plates is a much bigger problem. Thus, in this study, the thin EN AW$5083 \mathrm{H} 111$ plates were welded by applying low heat input with double pulse GMAW method. The effects of the used welding parameters on welding quality were investigated. Both macrography and micrography of the cross-sections of welded samples were investigated for metallographical examination by using optical microscopes (stereo and metal microscopes). Mechanical properties of samples were determined by hardness and tensile tests. In order to achieve the hardness distribution in the cross-sections of the welded samples, Vickers microhardness profiles test was carried out. It was observed that the pulse frequency of the current used in the welding process has significant effects on the joint strength. HAZ broadened with the increase in pulse frequency. Thus, it has been observed that the joint strength was adversely affected due to the broadening of the inhomogeneous zones in the sample cross-section.
\end{abstract}

Keywords: EN AW-5083 H111, DP-GMAW, mechanical properties, weldability

\section{Introduction}

The functions, materials, designs and thereby the weights of the various components of the machines or constructions that are used in daily life are an important research field. Usage of lighter moving parts in machines provide less energy consumption and accordingly the required energy decreases. This situation is an important factor to use energy efficiently without any decrease in workforce and protect the environment. As a result, different materials and material combinations are used to carry out all requirements in machines and constructions (Brumm \& Bürkner, 2015). Light engineering alloys are used significantly for energy conservation especially in 
aerospace, automotive and marine industries. Among various light engineering alloys, aluminum alloys come into prominence with their properties such as exceptional machinability, good formability, high specific strength and excellent corrosion resistance (Wang \& Xue, 2017), (Shi et al., 2017), (Dragatogiannis et al., 2016).

Aluminum alloys, with their light and durable properties, make it possible to use the more thinner plates/profiles in applications. Various mechanic fastening methods (bolts, screws, studs, rivets etc.) used in industry cause an increase in weight, high cost and time consumption. Considering this situation, the welding of thin aluminum alloy plates/profiles became a necessity to increase the energy efficiency of many machines. The efficiency and reproducibility of the welded joints in these materials have a profound effect on the quality of manufacturing processes and the economic feasibility (Brumm \& Bürkner, 2015). However, there are important problems that restrict the welding of aluminum alloys such as solidification cracking, porosity formation, the perforation of thin plate during welding, oxide layer at the surface of alloy and distortion and internal stresses formation in weld seam due to the high thermal expansion coefficient of the material (Gungor et al., 2014), (Wang \& Xue, 2017), (Zhu et al., 2015). Friction stir and diffusion welding methods are used to obtain high strength weld joints in aluminum alloy. But, some disadvantages, such as the low applicability of these solid-state welding methods in particular constructive joints, the unfilled hole formation due to the used tool at the end of the joint in FSW and additionally, a vacuum system necessity for diffusion welding limit the usage of these methods on a vast scale in advanced technological fields (Shang et al., 2012).

Aluminum alloys are welded commonly in the industry with gas tungsten arc (GTAW) and gas metal arc welding (GMAW) methods. However, it is almost impossible to obtain a good joint in the welding of thin aluminum alloy plates with these conventional methods. The inability in precise control of penetration during welding causes the perforation of plates or changing in the forms (shapes) of welding grooves (Feng et al., 2009). Furthermore, the solidification of aluminum alloys occurs rapidly due to high thermal conductivity and relatively low melting temperatures of material and thus, there is no time left for gas bubbles to escape from welding seam (Brumm \& Bürkner, 2015). The thin oxide layer (Al2O3) at the surface of alloy that has higher melting point than aluminum, should be also removed from the welding area with a suitable welding method after mechanical and chemical cleaning. Due to these situations in the welding of aluminum alloys, the required thermal input for material (although the melting point of aluminum is lower than steel) is almost the same with thermal input in steel welding (Brumm \& Bürkner, 2015). Therefore, the applied thermal input in the welding of aluminum alloys should be adjusted and controlled precisely to obtain a proper and high strength joint.

Several researches have been carried out in the literature to reduce defects in the welding of aluminum alloys and to obtain good weld joints and more suitable microstructure in the weld zone. Double-pulse gas metal arc welding (DP-GMAW) is an important method for joining aluminum alloys. Structurally high strength weld joints can be obtained economically with this method (Wang et al., 2017). In the DP-GMAW method, two sequential phases with different pulse characteristics are applied repeatedly. The current waveform of DP-GMAW (Fig. 1) consists of rhythmic thermal base (TB) and thermal pulse (TP) phases which are used to modulate the thermal diffusivity without changing the thermal input (Wang \& Xue, 2017), (Devakumaran et al., 2012). Thus, with appropriate pulse parameters in DP-GMAW, the heating and 
cooling times of the welding zone can be adjusted more precisely, energy efficiency is ensured and a more favorable microstructure and less porous weld seams are obtained (Wang \& Xue, 2017), (Wang et al., 2017). Particularly in studies on the welding of aluminum alloys with DP-GMAW (Liu et al., 2013), it was explained that the fine dendritic microstructure obtained instead of the coarse dendritic microstructure in the fusion zone. In this study, comparisons of microstructure, macrostructure and mechanical properties of thin EN AW-5083 H111 plates welded by using DP-GMAW method were done according to pulsed current parameters.

Figure 1: Schematic representation of DP-GMAW current waveform

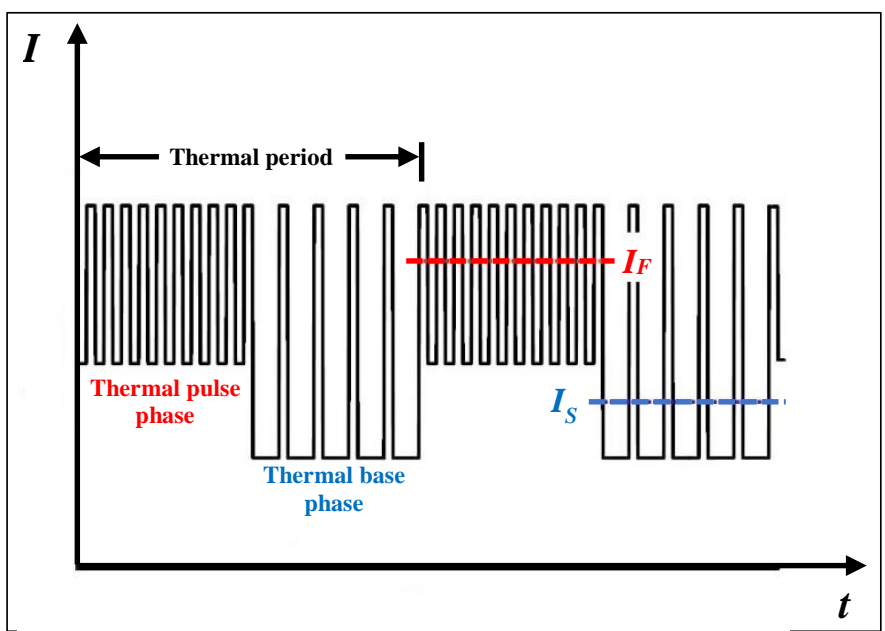

Source: (Wang \& Xue, 2017)

\section{Experimental Procedure}

\subsection{Welding Process}

In this study, EN AW 5083-H111 plates with a thickness of $2 \mathrm{~mm}$ were welded by using DP-GMAW method. Welding process was carried out according to DIN EN ISO 15614-2 standard and the plates were joined without preparing any welding groove. ER 5356 wire electrode with a diameter of $1 \mathrm{~mm}$ was used as filler material. The chemical compositions of weld wire and EN AW 5083-H111 alloy are given in Tab. 1. The aluminum alloy plates were prepared in the dimensions of $150 \mathrm{~mm} \times 300 \mathrm{~mm} \times 2 \mathrm{~mm}$ for butt welding. The oxide layer and contaminants at the surface of plates were cleaned mechanically and chemically before welding process respectively, with a stainless-steel wire brush and then with acetone. Commercial pure argon was used as shielding gas and gas flow rate was adjusted to $12 \mathrm{lt} / \mathrm{min}$ during the welding processes. The welding parameters used for the welding EN AW 5083-H111 plates of are given in Tab. 2. Welding torch was travelled with a mechanized system to maintain the travel speed constant during welding process. All welded joints were carried out at direct current electrode positive (DCEP) condition.

\subsection{Investigations on Weld Joints}

The cross-sections of welding zones of joined plates by DP-GMAW method were examined micrographically and macrographically with optical microscopes. The crosssections of the samples prepared for metallographical examination were ground by 
using SiC sandpapers with grit sizes 80-400-1200-2000. Then, prepared surfaces were polished with $00,5 \mu \mathrm{m}$ alumina suspension. To examine the microstructures of weld zones, the prepared cross-sections of samples were chemically etched firstly in $20 \mathrm{~g}$ $\mathrm{NaOH}+100 \mathrm{ml} \mathrm{H} 2 \mathrm{O}$ mixture, then $100 \mathrm{ml} \mathrm{H} 2 \mathrm{O}+1 \mathrm{~g} \mathrm{NaOH}+4 \mathrm{~g} \mathrm{KMnO} 4$ mixture. After the welding process, the tensile test specimens were prepared according to DIN EN ISO 4136 standard. Tensile tests were carried out at Schimadzu UH-F500KN universal test machine. Three tensile test specimens were prepared from every weld joint and the loading rate of tests was $2 \mathrm{~mm} / \mathrm{min}$. The tensile strength values of welded samples were determined by calculating the average mechanical values after tensile tests. Microhardness tests carried out with indentation load of $50 \mathrm{~g}(\mathrm{HV} 0,05)$ for 10 seconds by using a Vickers indenter in EMCO-Test DuraScan machine. Microhardness tests were done by considering the ISO 9015-1:2001 standard.

Table 1: Chemical compositions of EN AW 5083-H111 alloy and ER 5356 wire electrode

\begin{tabular}{lcccccccccc}
\hline Material & Si & Fe & $\mathbf{C u}$ & $\mathbf{M n}$ & $\mathbf{M g}$ & $\mathbf{C r}$ & $\mathbf{Z n}$ & $\mathbf{T i}$ & Other & Al \\
\hline $\begin{array}{l}\text { Base Material } \\
\text { (EN AW 5083-H111) }\end{array}$ & 0.4 & 0.4 & 0.1 & $0.40-1.0$ & $4.0-4.9$ & $0.05-0.25$ & 0.25 & 0.15 & 0.15 & Bal. \\
$\begin{array}{l}\text { Wire electrode } \\
\text { (ER 5356) }\end{array}$ & - & - & - & $0.05-0.20$ & $4.5-5.5$ & $0.05-0.20$ & - & $0.06-0.15$ & - & Bal. \\
\hline
\end{tabular}

Table 2: Welding Parameters

\begin{tabular}{cccccc}
\hline Sample & $\begin{array}{c}\text { Mean Current } \\
(\mathbf{A})\end{array}$ & $\begin{array}{c}\text { Voltage } \\
(\mathbf{V})\end{array}$ & $\begin{array}{c}\text { Frequency } \\
(\mathbf{H z})\end{array}$ & $\begin{array}{c}\text { Travel Speed } \\
(\mathbf{c m} / \mathbf{m i n})\end{array}$ & $\begin{array}{c}\text { Heat Input } \\
(\mathbf{J} / \mathbf{m i n})\end{array}$ \\
\hline DP1 & 50 & 17,5 & 22 & 25 & 210 \\
DP2 & 50 & 17,5 & 32 & 25 & 210 \\
DP3 & 60 & 19,1 & 12 & 40 & 172 \\
DP4 & 60 & 19,1 & 22 & 40 & 172 \\
\hline
\end{tabular}

\section{Results and Discussions}

In Fig. 2, macro views of the welding seam cross-sections of the samples joined with different welding parameters are given. According to the macro images, the lack of penetration and slag residues in the fusion zones of the samples were not detected. Pore formation was observed in the welding seams of DP2 and DP4 samples. However, it has been observed that the amounts and sizes of the detected pores do not adversely affect the welded joints when the tensile test results are taken into consideration. Depending on the porosity, it was determined that the welded samples have "B" quality level according to ISO 10042:2005(E) standard. Depending on the welding parameters, the excessive root penetration and excess weld metal sizes have also shown variance at the fusion zones of samples.

The welding of aluminum alloys with DP-GMAW method can be carried out with lower thermal input than the conventional GMAW method. Thus, the base material is less affected by heat in the weld joints obtained with DP-GMAW and furthermore, more-narrow heat affected zones (HAZ) form. This situation ensures the weld zone microstructure changes in a more-narrow zone and thus, inhomogeneous microstructure forms in the more-narrower zone. The formation of inhomogeneous 
microstructure in a narrower region increases the strength of joint. It is seen from Figure 2 that increasing the frequency of pulsed current result in a broadening of HAZ.

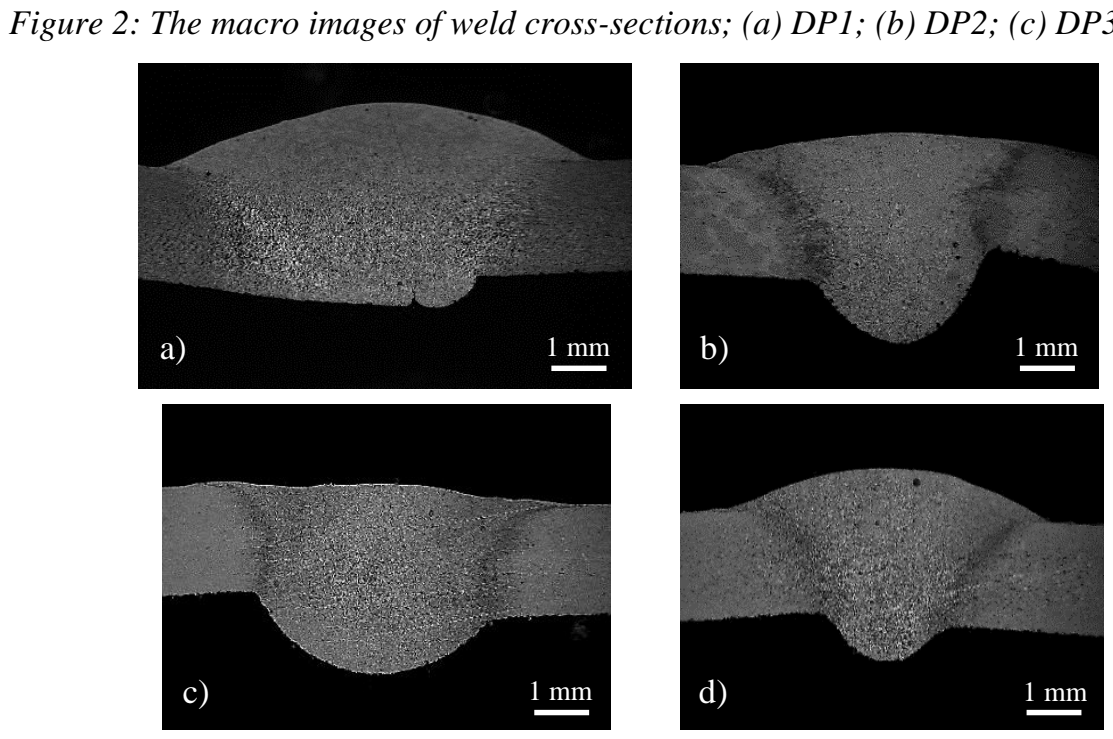

The HAZ and fusion zone microstructures of the samples are shown in Fig. 3. At the used current and voltage values, it was determined that the increase in the pulse frequency resulted in grain coarsening in the HAZ and fusion zone of the samples, relatively. The high heat conductivity coefficient of aluminum compared to steel increases the cooling rate after welding. Due to this rapid cooling in thin aluminum plates, no oriented coarse grains were determined in the fusion zone of any samples. Obtaining a finer and equiaxed homogeneous microstructure in the fusion zone prevented the decrease in strength that occurs due to grain coarsening in this zone.

The tensile strength results of welded samples were given in Fig. 4. According to the tensile tests, it was determined that the averages of yield strengths of the welded samples are approximately $186 \mathrm{MPa}$. The difference between the yield strengths of the samples can be negligible for the general strengths of the welded joints. When considering the characteristic tensile strength values specified for EN AW-5083 H111 in EN 1999-1-1:2007+A1 standard, the yield and ultimate tensile strengths (UTS) of the samples (except DP4) were obtained higher than the strength values of the base material. Furthermore, it was determined that the elongations of the welded samples are were lower than the elongation of the base material. The resultant rapid cooling due to the high thermal conductivity coefficient of aluminum after welding prevented excessive grain coarsening and increased the strength of samples. However, this rapid cooling decreased the elongations of welded samples by decreasing the deformability. After tensile tests, the ruptures occurred in HAZ for DP2 and DP4 samples. DP3 and DP1 samples failed in the fusion zone and base material, respectively.

Fig. 5 shows the hardness traverses of the welded joint cross-sections. The Vickers micro hardness measurements were carried out at mid-thickness of the sample crosssections. While each hardness measurement was done with $0.5 \mathrm{~mm}$ spacing in fusion zone and base material, it was done in HAZ with $0.25 \mathrm{~mm}$ spacing. When the hardness values are investigated, it is clearly seen that the hardness profiles of the DP2 and DP4 
samples showed similar behavior. While the average hardness of the base material zone of the welded sample is $80 \mathrm{HV}$, it was observed that this hardness value increased to $89 \mathrm{HV}$ on average in HAZ of these samples. In the DP3 sample, the maximum hardness value was determined in the fusion zone (average of 92). The hardness values varied depending on the zone changes in these sample cross-sections. The nonuniform mechanical property at the cross-section of the welded thin plate is a disadvantage with regard to not having homogeneous property in the welded joint. It was determined in DP1 sample that the hardness profile at the cross-section was uniform.

Figure 3: Microstructures of the sample cross-sections; (a) DP1; (b) DP2; (c) DP3; (d) DP4

a)

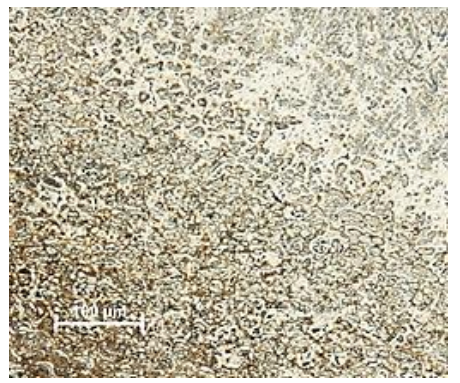

b)

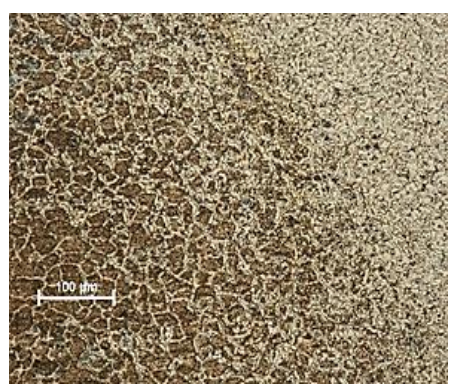

c)

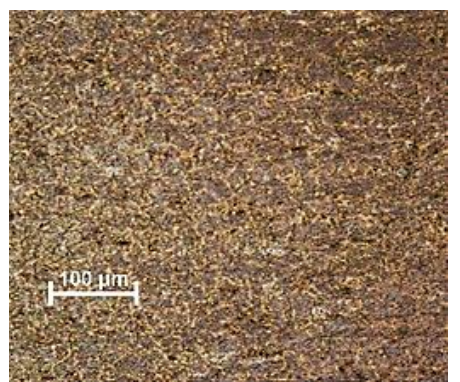

d)

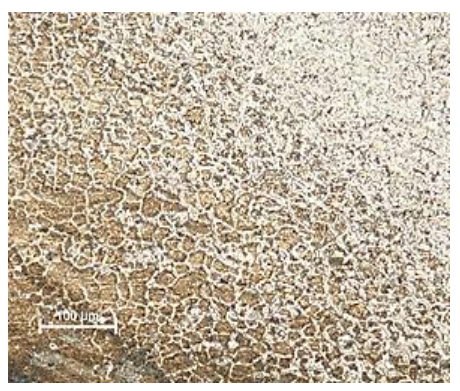

HAZ
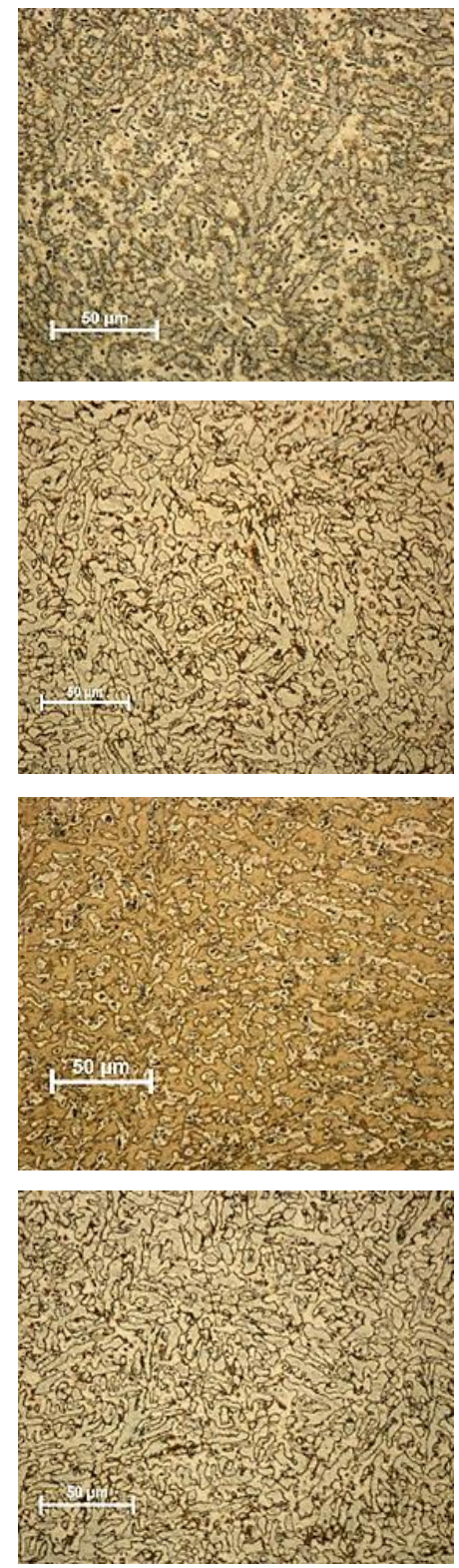

Fusion Zone 
International Academic Conference on Applied Research in Engineering, Science \& Technology

Figure 4: The average tensile strengths and elongation (\%) values of the welded samples ( $\sigma$ Y: Yield stress, oUTS: Ultimate tensile stress, $\varepsilon$ : Engineering strain)

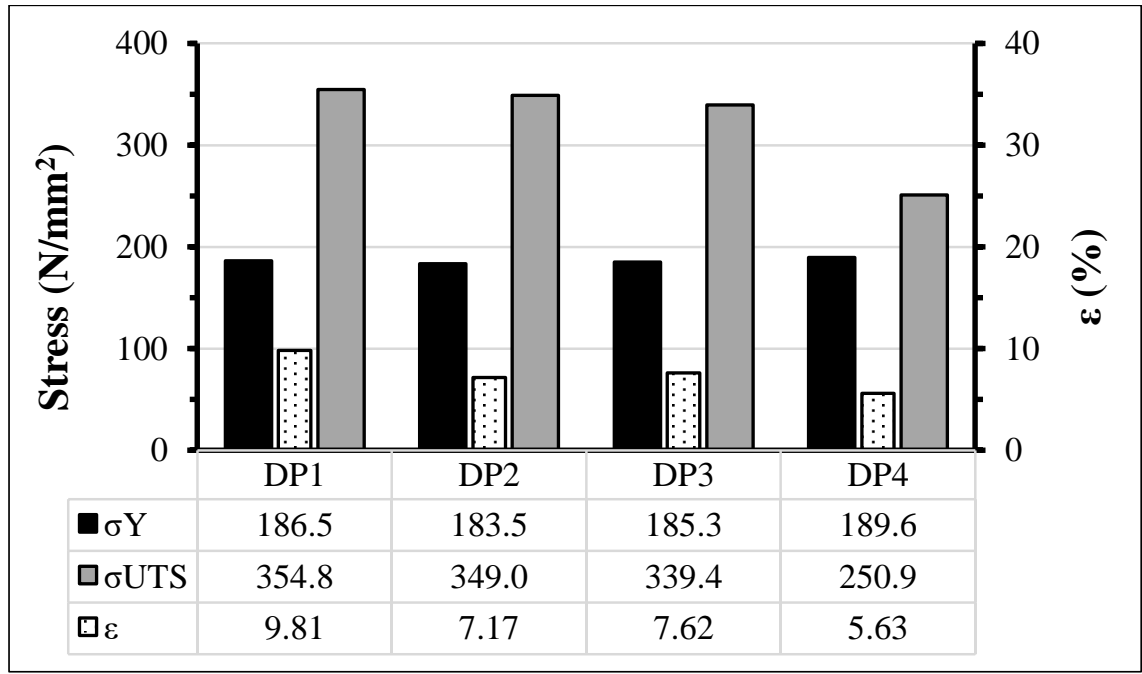

Figure 5: The Vickers micro hardness profiles of the sample cross-sections; (a) The hardness profiles comparison of the DP1 and DP2; (b) The comparison of the DP3 and DP4 samples
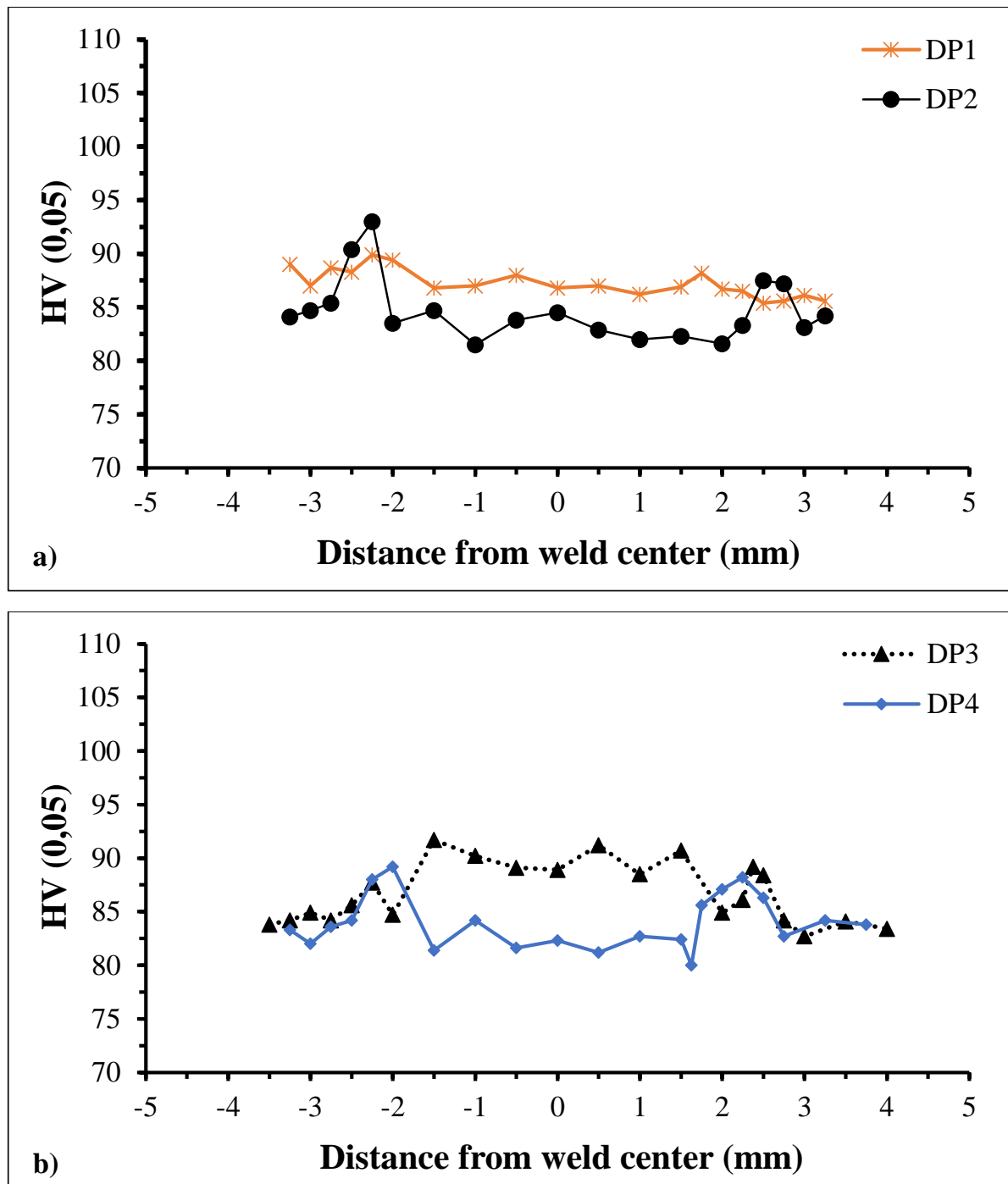


\section{CONCLUSION}

In the study, the microstructures, macrostructures and mechanical properties of the thin EN AW-5083 H111 alloy welded with DP-GMAW by using various parameters were investigated comparingly. According to macrography investigations, all used welding parameters provided good penetration in plate cross-section. Porosity was observed in the fusion zones of the DP2 and DP4 samples, but it was determined that this porosity amount is within the acceptable limits according to ISO 10042:2005(E) standard. In microstructure examinations, broadening of HAZ was observed by increasing the pulse frequency of the used current in the weld joint. Furthermore, the increase in pulse frequency resulted in grain coarsening relatively in the HAZ of welded samples. This situation gave rise to a relative embrittlement in HAZ and failure positions of DP2 and DP4 samples occurred in this zone after tensile tests. The yield and ultimate tensile stress values of the DP1, DP2 and DP3 samples obtained approximately same and additionally, it was determined that these measured values were higher from the characteristic mechanical properties of EN AW-5083 H111 according to EN 1999-1-1:2007+A1 standard. Considering the hardness profiles of the samples, the homogeneous hardness distribution was obtained in the cross-section of DP1.

\section{References}

[1] Brumm, S. and Bürkner, G. (2015). "Gas metal arc pulse welding with alternating current for lightweight materials," Materials Today: Proceedings, vol. 2, pp. 179-187.

[2] Wang, L. and Xue. J. (2017) "Perspective on double pulsed gas metal arc welding," Applied Sciences, vol.7, iss. 9.

[3] Shi, J., Zhou, Y. and Liu, L. (2017). "Application of pulsed laser-TIG hybrid heat source in root welding of thick plate titanium alloys," Applied Sciences, vol.7, iss. 5.

[4] Dragatogiannis, D.A., Koumoulos, E.P., Kartsonakis, I.A., Pantelis, D.I., Karakizis, P.N. and Charitidis, C.A. (2016). "Dissimilar friction stir welding between 5083 and 6082 Al alloys reinforced with TiC nanoparticles," Materials and Manufacturing Processes, vol. 31, iss. 16, pp. 2101-2114.

[5] Gungor, B., Kaluc, E., Taban, E. and S1k, A. (2014). "Mechanical and microstructural properties of robotic cold metal transfer (CMT) welded 5083-H111 and 6082-T651 aluminum alloys," Materials and Design, vol. 54, pp. 207-211.

[6] Zhu, Q., Xue, J., Yao, P., Dong, C., Wang, L., Heng, G. and Li, Z. (2015). “Gaussian pulsed current waveform welding for aluminum alloys," Materials and Manufacturing Processes, vol. 30, iss. 9, pp. 1124-1130.

[7] Shang, J., Wang, K., Zhou, Q., Zhang, D., Huang, J. and Li, G. (2012). "Microstructure characteristics and mechanical properties of cold metal transfer welding Mg/Al dissimilar metals," Materials and Design, vol. 34, pp. 559-565.

[8] Feng, J., Zhang, H. and He, P. (2009). "The CMT short-circuiting metal transfer process and its use in thin aluminium sheets welding," Materials and Design, vol. 30, iss. 5 , pp. $1850-1852$. 
[9] Wang, L.L., Wei, H.L., Xue, J.X. and DebRoy, T. (2017). "A pathway to microstructural refinement through double pulsed gas metal arc welding," Scripta Materialia, vol. 134, pp. 61-65.

[10] Devakumaran, K., Rajasekaran, N. and Ghosh, P.K. (2012). "Process characteristics of inverter type GMAW power source under static and dynamic operating conditions," Materials and Manufacturing Processes, vol. 27, iss. 12, 14501456.

[11] Liu, A., Tang, X. and Lu, F. (2013). "Study on welding process and prosperities of AA5754 Al-alloy welded by double pulsed gas metal arc welding," Materials and Design, vol. 50, pp. 149-155. 